\title{
Cloud Platform for Enterprise Financial Budget Management Based on Artificial Intelligence
}

\author{
Jing Qin and Qun Qin \\ Guangxi Technological College of Machinery and Electricity, Nanning 530007, China \\ Correspondence should be addressed to Qun Qin; qinq2021@gxcme.edu.cn
}

Received 2 August 2021; Accepted 24 August 2021; Published 25 September 2021

Academic Editor: Zhihan Lv

Copyright (c) 2021 Jing Qin and Qun Qin. This is an open access article distributed under the Creative Commons Attribution License, which permits unrestricted use, distribution, and reproduction in any medium, provided the original work is properly cited.

\begin{abstract}
Financial budget, as an important content of management accounting, is also an important way of business management. Budget basis comes from the financial accounting module, and the execution data source of the budget module is the financial accounting module's vouchers, accounts, and other data. They all exist on the UFIDA cloud platform. In recent years, artificial intelligence has made good progress in the field of science and technology and has a substantial effect on the development of real life. In addition, through the integration of other applications such as bank-enterprise direct connection, the company's economic business activities are directly converted into financial vouchers, and the budget module is managed and controlled when economic business occurs, so that these two systems work together to provide corporate management boost. Many data calculations are used in the financial budget. Many of these calculations are completed in the storage process, reduce network traffic, and improve system performance. The AI intelligent decision-making module uses advanced BI technology (machine learning, data mining, artificial intelligence) to integrate with the accounting activities and accounting functions between enterprises. The sales and management expenses have been effectively controlled, from an excess of $13.82 \%$ to not exceeding the budget. This research will help improve the company's overall budget management level.
\end{abstract}

\section{Introduction}

Traditional budget management is accomplished by manually receiving forms, filling in forms, submitting forms, and manual statistics. It is completely dependent on human activity and ignores the powerful capabilities provided by the information society. Problems in the process of financial risk prevention will inevitably have some problems. It is necessary to design a financial risk artificial intelligence research mechanism through the operability functions of artificial intelligence at this stage.

Nowadays, the business content of state-owned enterprises has become more and more complex, and the organizational structure has become increasingly large. The emergence of modern budget management systems got rid of the inefficient budget management methods of the past. Enterprises are the main driving force of social and economic development, an important source of national fiscal revenue, and an effective guarantee for solving the employment problem in a country with a large population.

Albrecht and Stone believe that they can predict various interesting attributes of the modeling agent. Although they discussed open issues, the effectiveness of these issues in the future is unknown [1]. Glauner et al. first outlined the definition of NTL and its impact on the economy. Although his research challenges some key parameters, these challenges have not been fully resolved [2]. Although Rongpeng gave an overview of AI and 5G cellular networks, he did not give an exact research plan [3]. Liu et al. believe that Fuzzy Petri Net (FPN) is a potential modeling technique; they did not have conclusive research data. Therefore, their research has no practical significance [4].

Financial budget management system mainly has functions such as budget preparation, budget adjustment, budget control, and budget analysis. Small- and medium-sized enterprises occupy a large proportion of all enterprises in 
our country. They not only inject fresh blood into the development of the national economy but also provide a large number of jobs and contribute to solving the problem of employment in a country with a large population. In addition, through the integration of other applications such as bank-enterprise direct connection, the company's economic business activities are directly converted into financial vouchers, and the budget module is managed and controlled when economic business occurs, so that these two systems work together to provide corporate management boost. UFIDA Financial Cloud provides enterprises with financial services centered on intelligent accounting and intelligent accounting, which can realize automatic and real-time financial accounting for enterprises. Financial statement and analysis services lead the financial transformation of enterprises to create new financial value. Many of these calculations are completed in the storage process and improve system performance.

\section{Corporate Financial Budget Management}

2.1. Artificial Intelligence. AI simulation of human behavior and thinking includes learning ability and perception, thinking style and logic, and behavior planning and decision-making. Alpha GO and unmanned driving are both top-level applications of artificial intelligence at present, but because they cannot have the same characteristics of logical reasoning and unstructured analysis as humans, they were in the stage of "executing" commands before [5].

The group basic education industry belongs to a relatively new research field, and there are few research results at present. Through the analytic hierarchy process, the risk assessment of a basic group is constructed, and the priority of artificial intelligence in the risk early warning and detection process is obtained.

The joint probability of $N$ observations, that is, the likelihood function is [6]:

$$
L(\alpha, \chi)=\prod P_{m}^{n}(1-P)^{Y}
$$

The maximum likelihood estimation is to obtain the estimated values of the parameters $\alpha$ and $\chi$, so that the probability of the $N$ observation values reappearing at random is the largest. The problem of maximizing likelihood function $L$ $(\alpha, \chi)$ can be transformed into a problem of maximizing $\log$ likelihood function $\ln L(\alpha, \chi)$ [7].

$$
\ln L(\alpha, \chi)=\ln \prod P_{m}^{n}(1-P)^{Y}
$$

Through computer iteration, the parameter estimation value $\alpha, \chi[8]$ can be obtained.

$$
\frac{\partial \ln L(\alpha, \chi)}{\partial \alpha}=\sum_{i=1}^{n}\left(y-\frac{e^{\alpha+\chi}}{1+e^{\alpha+\chi}}\right) .
$$

If the probability of accounting fraud in any sample company is $p$, the probability of no fraud or non-fraud is $1-\mathrm{p}$ [9]:

$$
\ln \frac{p}{1-p}=\beta+\beta_{1} x_{1}+\cdots+\beta_{n} x_{n}
$$

The linear logistic regression model can finally be written as the following expression [10]:

$$
\ln \frac{p}{1-p}=3.4+0.65 x_{1}+\cdots+0.631 x_{n}
$$

The principle of similar asset size takes the four-year average asset size of each sample, matching among companies whose average size does not fluctuate more than $20 \%$ sample [11]:

$$
\left|\frac{Z_{X}-Z_{Y}}{Z}\right| \leq 20 \%
$$

In the same way, we can see that the principle of "the number of employees is similar" takes the average number of employees in each sample average number of employees. The fluctuation ratio does not exceed $20 \%$ of companies select matching samples, that is [12]

$$
\left|\frac{Y_{M}-Y_{N}}{Y}\right| \leq 20 \%
$$

Among them, $Y_{M}, Y_{N}$ represents the average number of employees in samples $M$ and $N$ in four years [13].

2.2. Cloud Computing. Let $\mathrm{S}=(\mathrm{U}, \mathrm{A})$ be a decision table [14]:

$$
\begin{gathered}
\operatorname{POS}_{B}(D)=\operatorname{POS}_{C}(D), \\
\forall a \in B, \operatorname{POS}_{B-A}(D) \neq \operatorname{POS}_{B}(D) .
\end{gathered}
$$

Set $D$ is defined as [15]:

$$
\operatorname{ENT}(D)=-\sum_{x} p \log _{2} p_{n}
$$

Then, sample $D$ with attribute $a$ is [16]

$$
G(D, a)=\operatorname{ENT}(D)-\sum_{V=1}^{V}\left|\frac{D^{V}}{D}\right| .
$$

The "split information" value is used to normalize the information gain [17]:

$$
\operatorname{SENT}(D)=-\sum_{V=1}^{V}\left|\frac{D^{V}}{D}\right| \times \log _{2}\left|\frac{D^{V}}{D}\right| .
$$

This value indicates that the sample $D$ is divided into $V$ pieces of division information corresponding to the attribute a. The information gain rate is defined as follows [18]:

$$
\mathrm{GR}=\frac{G(D, a)}{\operatorname{SENT}(a)} .
$$


According to the corresponding index system, set the original data matrix [19]:

$$
M=\left[\begin{array}{ccc}
M_{11} & \cdots & M_{1 p} \\
M_{21} & \cdots & M_{2 p} \\
M_{n 1} & \cdots & M_{n p}
\end{array}\right]=\left(M_{1}, M_{2}, \cdots, M_{p}\right)
$$

$p$ is the number of selected listed companies.

$$
\mathrm{Y}_{i j}=\frac{X_{i j}-Y_{j}}{\beta_{j}} .
$$

$\beta$ is the correlation coefficient. Then, the object belongs to this category, and the basic Bayesian formula is as follows:

$$
P(C \mid X)=\frac{P(C) P(X \mid C)}{P(X)}
$$

$P(C)$ is the prior probability.

2.3. Financial Budget Management. Most of the business difficulties of SMEs stem from the financial crisis caused by factors such as their unreasonable capital structure, weak corporate governance system, and insufficient managerial experience. The comprehensive budget product under the cloud financial system used by the company provides the following support:

(1) Provide a budget system creation platform

A multidimensional budget system can be built on the cloud financial system platform. According to the company's needs, the budget system is under the unified management and control of the group, but it is also authorized to meet the company's centralized management application requirements. At the same time, it can be based on the actual branch situation. Flexible modification to meet the budget management needs of subsidiaries [20].

(2) Provide budget analysis and execution monitoring platform

Small- and medium-sized enterprises have their particularities. Due to their low entry barriers, market competition is fierce, and they have financial and nonfinancial risks such as insufficient financial management capabilities, imperfect corporate governance systems, lack of professionalism in managers, and difficulty in financing. According to the company's key needs, in addition to the normal budget management process and functions, this comprehensive budget management system also focuses on the settings of the budget analysis system and budget control system. You can also obtain data from the expense reimbursement system to process the quota occupancy, paving the way for the company's next fund management plan. The monitoring platform has early warning and control functions, infiltrates budget control into every node of daily business, and provides real-time monitoring, which effectively reflects the current budget implementation situation and assists relevant departments in budget management. The company's financial supervision is shown in Figure 1.

For the enterprise's financial cloud $Y$ :

$$
Y=\int \beta(\mathrm{x}) d x .
$$

Obtain all objective information through the above formula.

$$
V=Y
$$

Financial clouds are valuable.

$$
K=\int 1 V d V
$$

Among them, 1 is the knowledge conversion coefficient of useful information. The value of similar enterprises in the course of operation is comparable and can be used as a standard for evaluating the value of the enterprise for comparison. The basic calculation is

$$
\frac{V}{C}=\frac{V_{i}}{C_{i}}
$$

$V$ is the value of the enterprise to be assessed:

$$
V=\sum_{i=1}^{n} \frac{R}{(1+R)^{I}} .
$$

EVA is the English abbreviation of Economic Value Added. It was originally used to evaluate the business performance of the company and to measure the performance of the business during the inspection period.

$$
\mathrm{EVA}=\text { NOPAT }-\mathrm{WACC} \times \mathrm{TC} .
$$

The formula is as follows:

$$
K_{E}=R_{F}+\alpha\left(R_{M}-R_{F}\right) .
$$

$R_{F}$ is a risk-free reward:

$$
\text { wacc }=K(1-T) * \frac{D}{D+E}+K_{E} * \frac{D}{D+E} .
$$

$E$ is equity capital. The single-stage growth model means that the company's growth rate will remain the same every year in the future, and the company's growth rate will be very stable. The EVA single-stage model enterprise value formula is as follows:

$$
V_{1}=T_{0}+\sum_{t=1}^{n} \frac{\text { EVA }}{\text { wacc }-g} .
$$

Among them, $g$ is the growth rate. The two-stage growth 


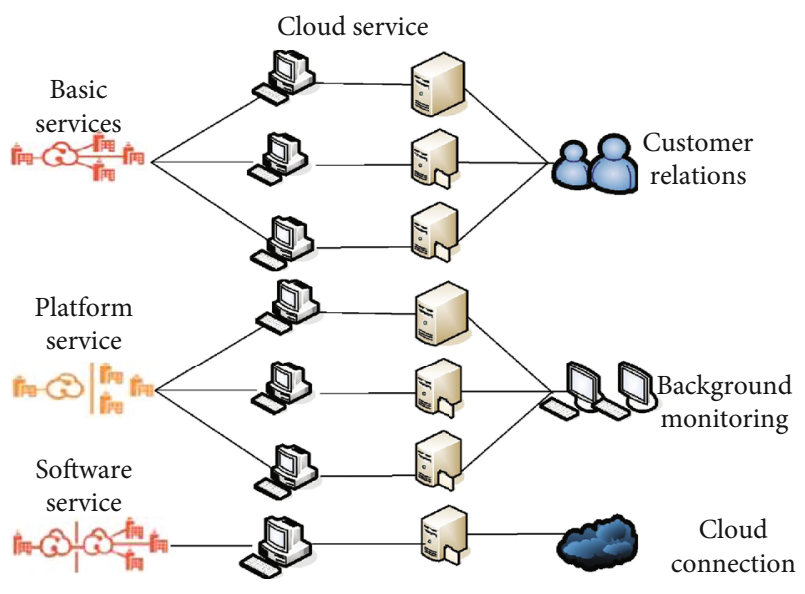

FIGURE 1: Corporate financial supervision.

model refers to the division of an enterprise's growth rate into two development stages, a high-speed development stage and a stable development stage. The EVA two-stage model enterprise value formula is as follows:

$$
V_{2}=T_{0}+\frac{\text { EVA }}{1+\text { wacc }}+\frac{\text { EVA }}{(1+\text { wacc })(\text { wacc }-g)} \text {. }
$$

\section{Enterprise Financial Budget Management Cloud Platform Experiment}

3.1. HaaS and laaS Layer Server Systems. In the traditional financial information system, the hardware and infrastructure include computer rooms and server equipment and other entities, which need to be prepared by users themselves. In the cloud financial system used in this research, these are all provided as services, and the company does not need to build computer rooms and purchase servers and other related hardware by yourself. The budget system built by the company at this stage needs to be connected to the financial system. Therefore, the financial system and the budget system need to be built on the same computer system and share one set which can facilitate the exchange and calculation of financial budget data and accounting data. With the continuous deepening of the reform of the corporate operating mechanism, modern corporate management has become a system management project composed of many subsystems such as human resource management, technology management, supply and marketing management, and financial management. Therefore, the budget management system will also use the HaaS and IaaS services provided by the UFIDA public cloud platform. Client: any microcomputer in AMD LAN. Network composition: LAN established by AMD. The main environment of the server is shown in Table 1.

3.2. Overall Logical Level of System Functions. The main function of the company's cloud financial system is financial budgeting, including the most basic general ledger and cash management. If the function is expanded in the future, it may also involve functions such as reimbursement manage- ment, receivables, and payable management, while the comprehensive budget management system mainly includes budgeting, budget adjustment, budget control, budget analysis, and other functions. The budget basis comes from the financial accounting module. They all exist on the UFIDA cloud platform. In addition, through the integration of other applications such as bank-enterprise direct connection, the company's economic business activities are directly converted into financial vouchers, and the budget module is managed and controlled when economic business occurs, so that these two systems work together to provide corporate management boost. This system function mechanism is not only suitable for investment enterprises like companies but also suitable for enterprises in manufacturing, energy, retail, and other industries. It has a certain degree of universality and reference.

The implementation of comprehensive budget management is conducive to clarifying the development goals of the enterprise and realizing the combination of long-term strategic planning and short-term strategy implementation. Starting from a financial perspective, the budget indicators are divided into operating income, operating costs, sales and management expenses, financial expenses, capital expenditures, etc., because the business scope of each subsidiary is different, so the operating income and operating costs are divided by business. The scope is refined. Sales and management expenses are mainly divided into employee compensation and official expenses. The company's investment business has specific construction projects corresponding to it. The project can determine the payment plan according to the contract. Therefore, the budget indicators for this part are mainly the name and construction content of each project. The company also designed cash inflow and outflow indicators. The overall logic level is shown in Figure 2.

3.3. Database Layer. The database is an important part of the system. The quality of the database will directly affect the success or failure of the system development and the performance of the system. We have created Fin_Copy_Revision, Fin_Alloc_Deprecation, Fin_Electronic_Calculation, Fin Unit_Cost_Calculation, Fin_Version_Layout_2_Month, and other storage procedures in the database library to copy the financial data subversions, the depreciation of fixed assets, the calculation of electricity costs, the calculation of product unit costs, and so on. We decide whether to use cursors according to whether speed is a priority. Many of these calculations are completed in the storage process.

3.4. AI Intelligent Decision-Making Module. With the development of the economy and the continuous expansion of the scale of enterprises, as well as the continuous innovation of management theory, budget management should also continue to establish new concepts while adhering to traditional excellent concepts to adapt to today's increasingly complex economic environment. The AI intelligent decision-making module uses advanced BI technology (machine learning, data mining, artificial intelligence) to integrate with the accounting activities and accounting functions between enterprises. Model mainly includes the following parts: 
TABLE 1: Main server environment.

\begin{tabular}{lcc}
\hline & Operating system & Microsoft Windows 2000 Server, IIS \\
Service-terminal & Database systems & Microsoft SQL Server 200 \\
& Version control tools of the original code & VSS (MS Visual Source Save) \\
Client side & Operating system & Microsoft Windows 2000NT WorkStation/2000 professional/XP \\
\hline
\end{tabular}

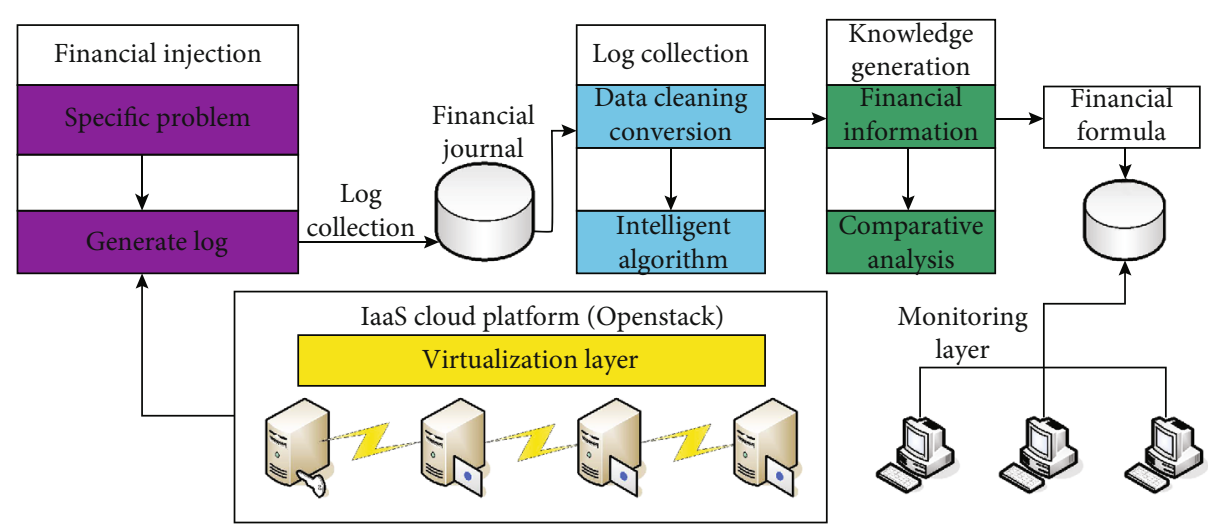

Figure 2: Overall logical hierarchy.

(1) Data Source Layer. It mainly includes multisource heterogeneous data integration. These data include some internal enterprise data: ERP, SCM, SRM system data generated by the production, marketing, and storage system, enterprise intranet office data (OA system data), and enterprise external data: internet platform data, institutional statistical data, etc. For these multisource heterogeneous data, enterprises need to reduce the noise of the data, that is, through a certain method to make the data convenient for business analysis. Specifically, two different methods are mainly used: one is to use ETL technology to connect the daily business data of the enterprise (ERP, OA, SCM, SRM, and other system data) and the database of relevant government departments and use certain methods to perform the data. Stored in the enterprise-level data warehouse sharing platform to provide data support for business decision-making

(2) Four-Database System. It mainly includes data warehouse system, model library system, method library system, and knowledge base system. It is conducive to the implementation of the "economic responsibility system" for enterprises to promote the process of enterprise reform, which is deduced by accounting theory core. Among them, the data warehouse mainly comes from the standardized data processed by ETL.XBRL and other technologies at the data source layer. The model library and method library mainly include (1) all models of management accounting business decision-making, the main tools and methods in the application field of management accounting, such as financial analysis models, financial forecasting models, financial early warning models, performance evaluation models, and strategic analysis tools; (2) data mining models and methods, such as neural networks, cluster analysis, and principal component analysis; (3) machine learning and deep learning, fractal technology, deep stacking network algorithm, etc.; (4) many source heterogeneous information fusion algorithms, such as evidence theory; and (5) fusion of multiple methods. The knowledge base is an expert knowledge system based on the principles of expert knowledge, decision rules, and inference engines. The system home page is shown in Figure 3

(3) Intelligent Decision Support System Platform. It mainly includes decision processing layer and problem processing and human-computer interaction layer. The decision-making processing layer mainly uses OLAP multidimensional analysis, intelligent decision-making, intelligent analysis, dynamic monitoring, and adjustment methods. The humancomputer interaction system mainly realizes two main functions, namely, data visualization and selfservice data management. Data visualization mainly lies in the page display link of indicator data. It uses different display methods such as pictures, tables, text, dashboards, or data consoles and customizes the display according to the characteristics of the data, and the result displays requirements and realizes the mutual penetration of data. Drill down through and data. That is if the problem is found in the report link, you can directly query the certificate link by drilling down layers, so that the problem is clear at a glance and has a root to follow. Self- 


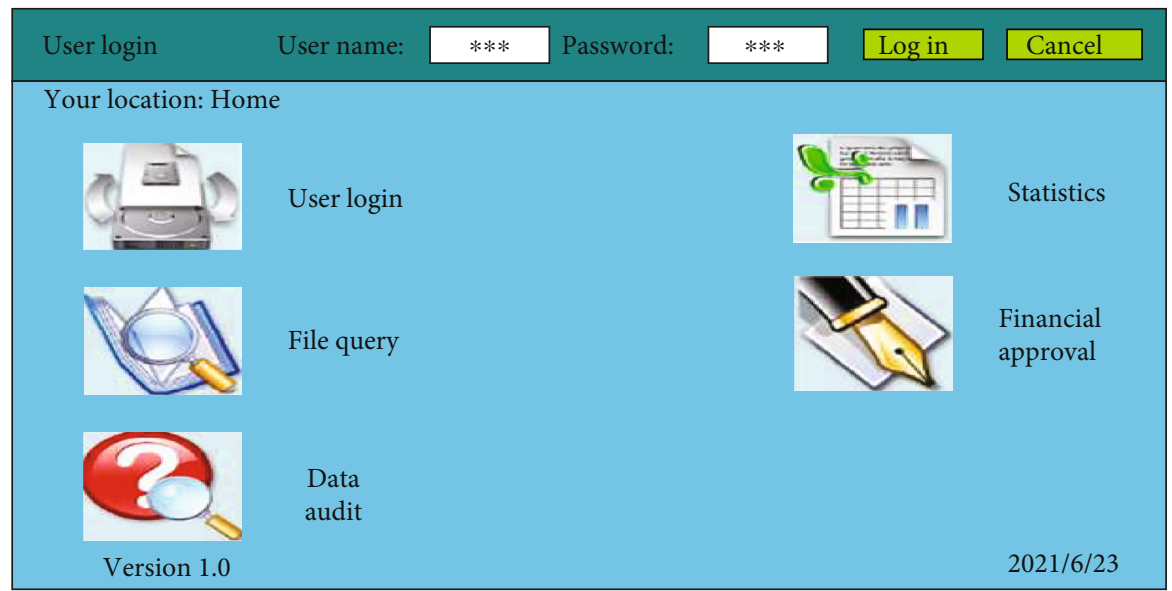

FIgURE 3: System home page.

service data management is mainly used to meet the personalized analysis needs of users (usually business personnel and analysts). Specifically, the data processing authority is delegated to the business layer or management users, so that they have ETL capabilities and visually process data. Users can self-service from the data warehouse by filtering fields, establishing connections between tables and establishing views. Access data freely create business data analysis models of different topics and realize collaborative sharing. This plan is conducive to enterprises to determine a reasonable management mechanism and operation mechanism, coordinate and balance the relationship between all parties, and realize the comprehensive allocation of resources

\section{Results and Discussion}

The upload file information table in the database records the information of each uploaded file, the sending time is consistent with the corresponding upload time of the report, and the storage address is the corresponding storage location of the corresponding Excel file in the server. The database upload files are shown in Table 2.

The "Serial Number" item in Table 3 is designed as an identification position with an increment of 1 , so that when the user adds data to Table 3 , this item can be automatically obtained. This method is not only convenient for the data in the database. The statistical work of a large amount of data is easy to operate. Most of the data types in the table are set to string, and the length is 255 , so that the table has a certain fault tolerance. The upload time is date time type, which requires strict format entry for this point; it will be further explained it. The user data is shown in Table 3.

Enterprises strengthen the basic work of various management, control daily economic activities, and improve the level of enterprise management. The preparation of a comprehensive budget is the starting point for business management and control of daily economic activities. We investigated the necessity of financial budget implementation from two levels of the enterprise. One level is whether
TABLE 2: Database upload files.

\begin{tabular}{lcc}
\hline Column name & Type of data & Length \\
\hline Send time & Datetime & 8 \\
Company name & IYar char & 200 \\
Storage address & Nvar cher & 200 \\
File name & Nvar char & 200 \\
Report year & Char & 6 \\
Report month & Char & 4 \\
Serial number & Int & 4 \\
\hline
\end{tabular}

TABLe 3: User data.

\begin{tabular}{lcc}
\hline Column name & Type of data & Length \\
\hline Serial number & Int & 4 \\
Project number & Nvar char & 255 \\
Project name & Nvar char & 255 \\
Total investment & Nvar char & 255 \\
Total duration & Nvar char & 255 \\
Total construction scale & Nvar char & 255 \\
\hline
\end{tabular}

the company should implement the financial budget, and the other level is the reasons that affect the implementation of the financial budget, and the reasons are arranged in order of importance. The managers of the units of the survey respondents think that financial budget management should be implemented accounted for $99.25 \%$. Almost all survey respondents believe that financial budgeting should be implemented. The internal management needs of enterprises accounted for $96 \%$ of the reasons for the implementation of financial budgets. The pressure accounted for $27 \%$, and $61.11 \%$ believed that both of them and the internal management needs of the enterprise were significant. This shows that financial budgets are widely used in enterprises, and their internal management needs are the main driving factors. The survey of the implementation of corporate financial budgets is shown in Figure 4. 


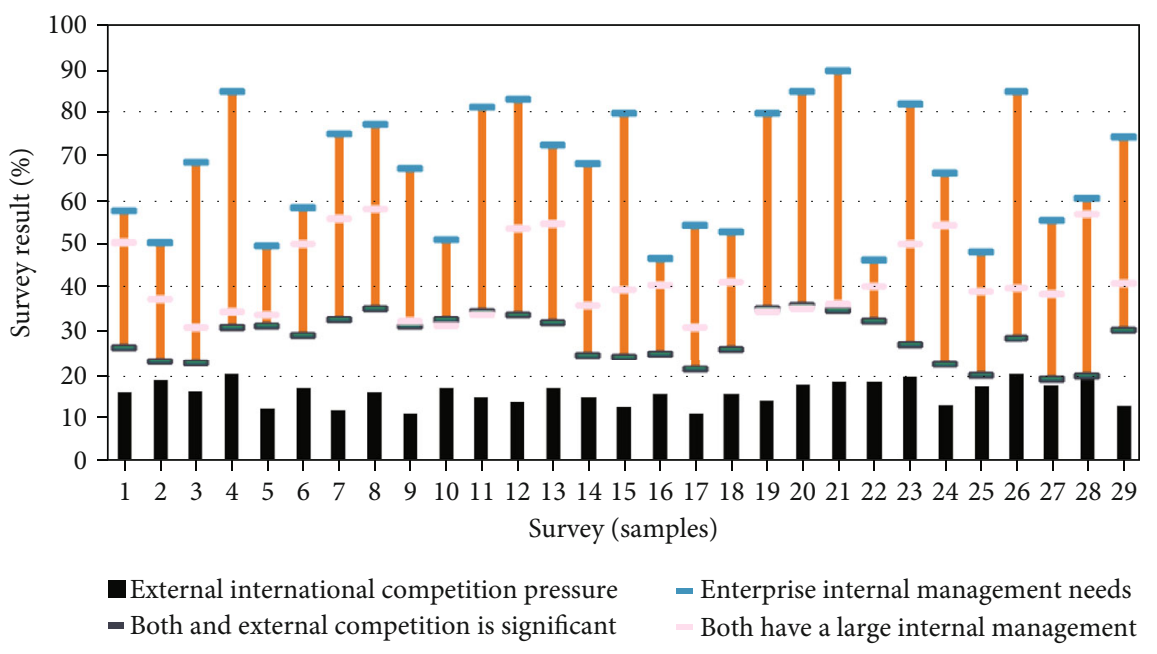

FIgURE 4: Implementation survey of corporate financial budget.

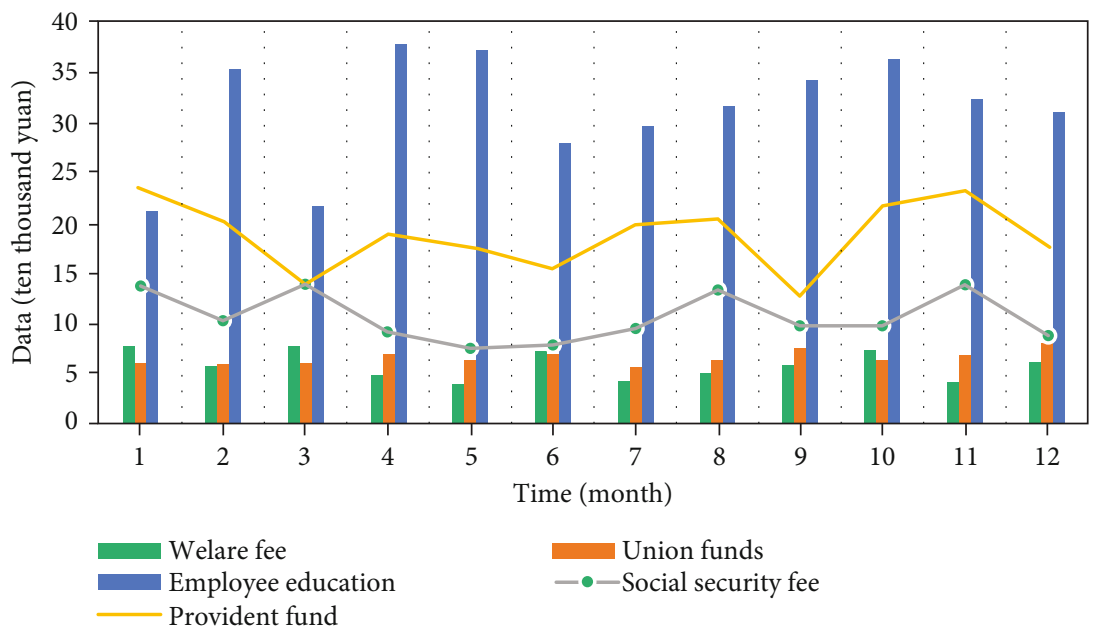

Figure 5: The company's financial budget for 2019.

The results of the comparative analysis of the budgeted and actual numbers in the company's 2019 annual operating budget show that the actual number of operating profits did not meet expectations, mainly because operating income did not meet expectations, which was $27 \%$ worse, and sales and management expenses exceeded the budget $13.82 \%$. At the same time, the financial expenses are also a lot in excess. The main reason is that the company added some new investment projects in 2019, which led to an increase in the handling fees of financial institutions. The company did not predict this well. This problem can be improved through a wider range of data sources and more powerful data calculation functions in the comprehensive budget system under the cloud accounting system. Due to the openness and integrated functions of the cloud accounting platform, more historical background data of budget-related applications can be obtained, and the company can also incorporate more nonfinancial indicators into the budget management system, which cannot be achieved by traditional budget management systems. The company's financial budget for 2019 is shown in Figure 5.

It can be seen that compared with the previous 2019 data, due to the company's 2020 budget system under the cloud accounting system, the budget accuracy has been greatly improved. This is due to the rigid control and early warning effect of the budget system under the cloud accounting system. The budget cannot be recorded in the account, or the additional adjustment approval process is used to promote the main body of each department to avoid unnecessary expenses. Through the effective function of the budget system, the company's total profit in 2018 exceeded the expected $10.17 \%$, and the company's losses were effectively reduced. On the other hand, the company's cost-toincome ratio has also been reduced from 3.87 to 2.55 , and the company's operating efficiency has been effectively improved. Judging from the current year, due to the role of 


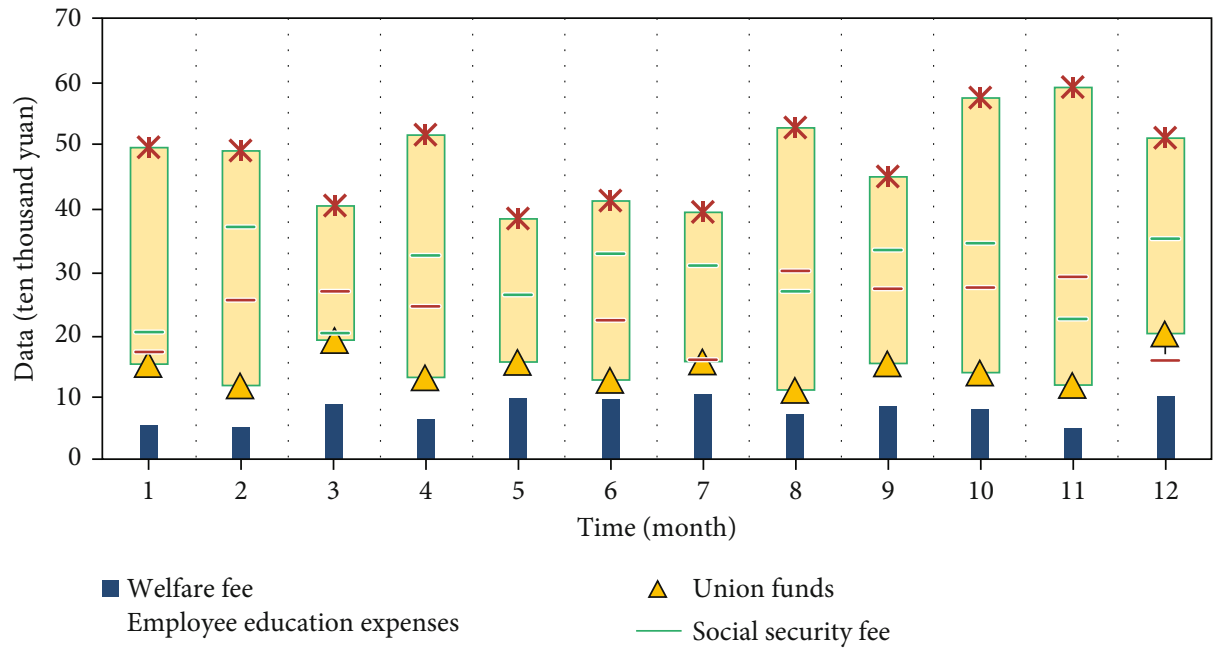

Figure 6: The company's financial budget for 2020.

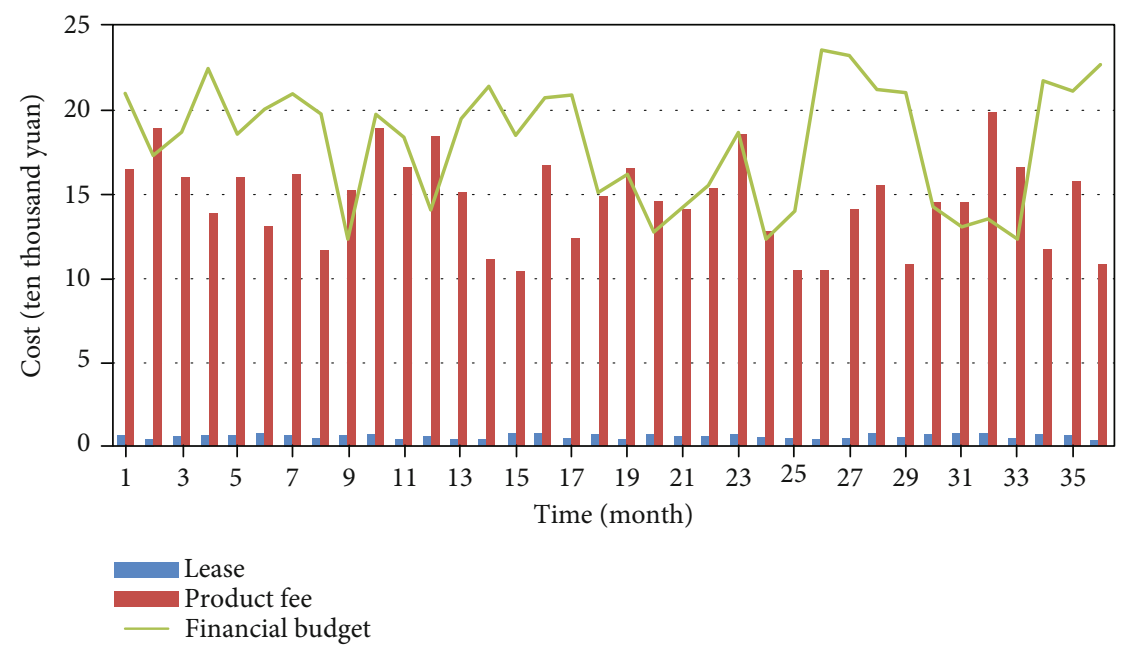

Figure 7: Comparison of the construction cost of the comprehensive budget system under the company's cloud financial system and the construction cost of the traditional model.

the fixed asset module in the accounting system, depreciation expenses can be accrued to get the budget, so that the final difference is zero. The company's 2020 financial budget is shown in Figure 6.

Servers generally have a three-year warranty period. After the warranty period, you need to pay additional premiums, and key business will be affected after three years. The three-year period is used here. Dell servers will not incur maintenance costs within three years. The three-year UFIDA cloud product cost is 225,600 yuan, the cloud server lease fee is 8,220 yuan, and the total cost of the financial budget management system under the cloud financial system is 233,820 yuan. Therefore, it can be seen that the construction cost of the comprehensive budget system under the company's cloud financial system is almost $60 \%$ less than the construction cost of the budget system under the traditional model. Figure 7 shows the comparison between the construction cost of the comprehensive budget system under the company's cloud financial system and the construction cost of the traditional model. Finding out the problem, analyzing the reason, and improving the future work are also to implement fair rewards and punishments for employees, so as to reward diligence and punish laziness, mobilize employees' enthusiasm, and encourage employees to work together.

The company's current application of UFIDA cloud products is more convenient to operate than traditional financial software, and the design is more user-friendly. UFIDA's standard human-day quotation under the traditional software model and the implementation of the human-day quotation under the cloud mode given budget organizations of the enterprise are shown in Table 4. It can be seen that the implementation cost of the product under the cloud mode is also higher. It is reduced by $25 \%$ in software mode. 
TABLE 4: Implementation of standard human-day quotation and implementation of human-day quotation in cloud mode.

\begin{tabular}{lcccr}
\hline Mode & Budget module & Standard man-day & Unit price per person per day (yuan) & Total (yuan) \\
\hline Software mode & Budget & 60 & $¥ 2,000.00$ & $¥ 120,000.00$ \\
Cloud mode & Budget & 45 & $¥ 2,000.00$ & $¥ 90,000.00$ \\
\hline
\end{tabular}

\section{Conclusion}

Based on the prediction of the company's future activities and reasonably decomposing these activities among various departments can the company's budget indicators be close to reality. Ensure the smooth implementation of various value-added activities of the enterprise. Financial budget management system mainly has functions such as budget preparation, budget adjustment, budget control, and budget analysis. The budget basis comes from the financial accounting module, and the execution data source of the budget module is the financial accounting module's vouchers, accounts, and other data. In addition, through the integration of other applications such as bank-enterprise direct connection, the company's economic business activities are directly converted into financial vouchers, and the budget module is managed and controlled when economic business occurs, through the joint action of the two systems, it provides $\mathrm{AI}$ intelligent decision-making module for enterprise management. In the process of using advanced Bi Technology (machine learning, data mining, artificial intelligence), it is deeply integrated with enterprise accounting activities and functions to improve the intelligent decision-making level of the system. This research will help improve the company's overall budget management level. The product functions will be more complete, the management methods will be more scientific, the application restrictions will be less, and the system will be more mature. I also believe that more scholars will conduct research on the application of business management accounting in different industries in the cloud technology environment and make greater breakthroughs.

\section{Data Availability}

We did not obtain analytical permission from the data provider because of trade confidentiality.

\section{Conflicts of Interest}

The authors declare that they have no conflicts of interest.

\section{Acknowledgments}

This work was supported by the Key subject of vocational education reform in Guangxi: research and practice of personalized talent training mode based on the diversification of Higher Vocational Students (GXGZJG2019A013).

\section{References}

[1] S. V. Albrecht and P. Stone, "Autonomous agents modelling other agents: a comprehensive survey and open problems," Artificial Intelligence, vol. 258, pp. 66-95, 2018.
[2] P. Glauner, J. A. Meira, P. Valtchev, R. State, and F. Bettinger, "The challenge of non-technical loss detection using artificial intelligence: a survey," International Journal of Computational Intelligence Systems, vol. 10, no. 1, pp. 760-775, 2017.

[3] M. Hu, Y. Zhong, S. Xie, H. Lv, and Z. Lv, "Fuzzy system based medical image processing for brain disease prediction," Frontiers in Neuroscience, vol. 15, 2021.

[4] H. C. Liu, J. X. You, Z. W. Li, and G. Tian, "Fuzzy Petri nets for knowledge representation and reasoning: a literature review," Engineering Applications of Artificial Intelligence, vol. 60, pp. 45-56, 2017.

[5] A. Etminaniesfahani, A. Ghanbarzadeh, and Z. Marashi, "Fibonacci indicator algorithm: a novel tool for complex optimization problems," Engineering Applications of Artificial Intelligence, vol. 74, pp. 1-9, 2018.

[6] A. Al-Quran and N. Hassan, "The complex neutrosophic soft expert set and its application in decision making," Journal of Intelligent \& Fuzzy Systems, vol. 34, no. 1, pp. 569-582, 2018.

[7] T. Hester and P. Stone, "Intrinsically motivated model learning for developing curious robots," Artificial Intelligence, vol. 247, pp. 170-186, 2017.

[8] X. Peng and J. Dai, “Approaches to Pythagorean fuzzy stochastic multi-criteria decision making based on prospect theory and regret theory with new distance measure and score function," International Journal of Intelligent Systems, vol. 32, no. 11, pp. 1187-1214, 2017.

[9] M. Hutson, "Artificial intelligence faces reproducibility crisis," Science, vol. 359, no. 6377, pp. 725-726, 2018.

[10] M. Nasr, A. Mahmoud, M. Fawzy, and A. Radwan, “Artificial intelligence modeling of cadmium (II) biosorption using rice straw," Applied Water Science, vol. 7, no. 2, pp. 823831, 2017.

[11] W. Xue, Z. Xu, X. Zhang, and X. Tian, "Pythagorean fuzzy LINMAP method based on the entropy theory for railway project investment decision making," International Journal of Intelligent Systems, vol. 33, no. 1, pp. 93-125, 2018.

[12] M. J. del Moral, F. Chiclana, J. M. Tapia, and E. HerreraViedma, "A comparative study on consensus measures in group decision making," International Journal of Intelligent Systems, vol. 33, no. 8, pp. 1624-1638, 2018.

[13] S. D. Baum, "On the promotion of safe and socially beneficial artificial intelligence," AI \& Society, vol. 32, no. 4, pp. 543$551,2017$.

[14] C. Zhou, W. Tang, and R. Zhao, "An uncertain search model for recruitment problem with enterprise performance," Journal of Intelligent Manufacturing, vol. 28, no. 3, pp. 695-704, 2017.

[15] W. Jiang, B. Wei, X. Liu, X. Li, and H. Zheng, "Intuitionistic fuzzy power aggregation operator based on entropy and its application in decision making," International Journal of Intelligent Systems, vol. 33, no. 1, pp. 49-67, 2018.

[16] A. Youssef, M. El-Telbany, and A. Zekry, "The role of artificial intelligence in photo-voltaic systems design and control: a 
review," Renewable \& Sustainable Energy Reviews, vol. 78, pp. 72-79, 2017.

[17] J. J. Zhang, F. Y. Wang, Q. Wang et al., "Parallel dispatch: a new paradigm of electrical power system dispatch," IEEE/CAA Journal of Automatica Sinica, vol. 5, no. 1, pp. 311-319, 2018.

[18] G. Rodrigues de Campos, P. Falcone, R. Hult, H. Wymeersch, and J. Sjoberg, "Traffic coordination at road intersections: autonomous decision-making algorithms using model-based heuristics," IEEE Intelligent Transportation Systems Magazine, vol. 9, no. 1, pp. 8-21, 2017.

[19] A. Raghav, Z. A. Khan, R. K. Labala, J. Ahmad, S. Noor, and B. K. Mishra, "Financial burden of diabetic foot ulcers to world: a progressive topic to discuss always," Therapeutic Advances in Endocrinology and Metabolism, vol. 9, no. 1, pp. 29-31, 2018.

[20] H. Chen, Y. Zhu, K. Hu, and X. Li, "Virtual enterprise risk management using artificial intelligence," Mathematical Problems in Engineering, vol. 2010, Article ID 572404, 20 pages, 2010. 